\title{
Firearms Effects on Tsimane' Hunting and Traditional Knowledge in Bolivian Amazonia
}

\author{
Armando Medinaceli ${ }^{1^{*}}$ and Robert J. Quinlan ${ }^{1}$ \\ ${ }^{1}$ Department of Anthropology, Washington State University, Pullman, USA. \\ *armando.medinaceli@wsu.edu
}

\begin{abstract}
Subsistence hunting is a key activity for indigenous Amazonian people. Traditional Tsimane' bow hunting was strongly affected by the introduction of firearms over 30 years ago. Tsimane' of Bolivia maintain traditional hunting techniques with bows and arrows, sometimes in conjunction with modern firearms. This study explores Tsimane' perceived costs and benefits of bow- versus gun-hunting. We consider cultural conservation in addition to factors typical in ecological comparisons of traditional and introduced hunting technologies. Firearms are expensive and less reliable than bows and arrows. Costs of purchasing firearms requires market engagement and surplus production to generate cash. Tsimane' do not identify overhunting as one of the costs of firearms; though multiple studies show reduced game populations in areas under moderate to intense gun-hunting pressure. In sum, Tsimane' identify multiple benefits to traditional hunting technology, while firearms have a strong effect of the loss of knowledge regarding fabrication of bows and arrows, and present a challenge to Tsimane' cultural identity as bow-hunters.
\end{abstract}

Received November 11, 2017

OPEN ठACCESS

Accepted May 12, 2018

DOI 10.14237/ebl.9.2.2018.1154

Keywords Tsimane', Traditional hunting, Firearms, Bolivia, Amazonia

Copyright (C) 2018 by the author(s); licensee Society of Ethnobiology. This is an open-access article distributed under the terms of the Creative Commons Attribution-NonCommercial 4.0 International Public License (https://creativecommons.org/licenses/by-nc/4.0), which permits non-commercial use, distribution, and reproduction in any medium, provided the original author and source are credited.

\section{Introduction}

Wild fauna are the main protein source for many indigenous Amazonian groups (Robinson and Redford 1991), and hunting is central to their cultural dynamics and lifestyle based on specialized knowledge and skills passed down over generations (Carniero 1974; Rosélis et al. 2000; Vickers 1984). For Amazonian indigenous groups hunting is strongly linked with masculine identity and it is the most prestigious subsistence activity (Alexiades 1999; Gurven and von Rueden 2006). Prestige related to hunting may decline with acculturation (von Rueden et al. 2008), which could influence conservation of traditional knowledge. Key behaviors central to traditional hunting identity include 1) learning to make hunting equipment, 2) hunting skills developed through years of constant practice, and 3) acquisition of traditional ecological knowledge of plants and animals (Zent 2007). All of these key behaviors may have been altered by the introduction of firearms in Amazonia.

Hunting with traditional technology appears to be ecologically sustainable in lowland South America at current human population densities (Levi et al. 2009; Shepard et al. 2012). Introduction of firearms among tropical forest hunters, however, can have multiple effects on conservation of natural and cultural resources. In the Neotropics, firearms substantially improve short-term hunting efficiency relative to bow -hunting-greater probability of kill per encounter and returns in kgs per hour hunting (Alvard and Kaplan 1991; Gurven et al. 2006; Hames 1979; see also Jerozolimski and Peres 2003). Improved efficiency, however, comes with multiple "externalities" or hidden costs. Neotropical gun hunting appears to deplete game species in short periods of time. A large-scale, 10-year study of Amazonian subsistence hunting has shown that vertebrate biomass was reduced from $1200 \mathrm{~kg} / \mathrm{km}^{2}$ in areas with little hunting pressure to $200 \mathrm{~kg} / \mathrm{km}^{2}$ in areas under intense gun hunting, even with stable and declining human populations (Peres 2000). Models and simulations based on ethnographic data for Amazonian hunting indicated that limited use of firearms can drive prey populations to local extinction 
over a single human lifetime, and gun-hunting pressure may be acute for primate prey species (Levi et al. 2009, 2011; Shepard et al. 2012; cf. Alvard 1995; see also Cronin et al. [2016] and Kümpel et al. [2008] for gun-hunting effects on primates in West and Central Africa).

Costs of gun-hunting beyond wildlife conservation are less well documented, though studies suggest effects on traditional livelihoods and social relations. Firearms and ammunition are costly and oblige subsistence hunters to engage in cash economies that can alter traditional livelihoods (Hames 1979; Harner 1972). Costs of firearms and ammunition can also motivate prey choice for large species, complicating conservation efforts (Jerozolimski and Peres 2003:420; Siren and Wilkie 2016). Firearms can substantially increase the lethality of conflicts between people (Descola 1994:228; Hames 1979:228), potentially straining traditional social controls. Firearms can drastically alter individual social status when there is differential access to them (Holmberg 1969:274-276). The introduction of firearms can erode traditional patterns of cooperative hunting (Hames 1979). Studies focused on emic perceptions of firearms and gun hunting are especially scarce, though fragments (sometimes indexed, sometimes not) appear embedded in ecological studies and broader ethnographies. Even less well documented are effects of gun-hunting on conservation of ethnobiological knowledge and traditional technology.

Firearms are now ubiquitous among hunters in the Neotropics (Jerozolimski and Peres 2003); however, traditional bow-hunting continues alongside gun-hunting in some remote areas like Tsimane' communities in Bolivian Amazonia, described here. We focus on Tsimane' perceptions of gun- versus bow-hunting to help fill gaps in the ethnographic record. We examine the locally perceived costs and benefits of bows and guns, and consider effects of firearms on the conservation of 'Tsimane' traditional knowledge. We find that although firearms are more efficient than traditional bows and arrows, gunhunting contributes to a loss of traditional knowledge and alters Tsimane' identity. In their own words, the use of firearms "does not represent what a Tsimane" hunter really is."

\section{Methods and Setting}

Tsimane' have been described as foragerhorticulturalists (e.g., Gurven et al. 2006) with subsistence practices including hunting, gathering, and fishing of wild resources along with production of domestic crops. They usually construct settlements along rivers and more recently along roads (ReyesGarcia et al. 2012). Staple crops from swidden horticulture include manioc, rice, and plantain. Tsimane' are active hunters particularly of wild mammals including peccaries, pacas, deer, and monkeys, and fish for pacu, pintado, and bagre. More detailed descriptions of 'Tsimane' culture and society can be found in Ellis (1996) and Reyes-Garcia (2001). This study includes two Tsimane' villages in Beni Department of Bolivia: Cuchisama (20 households), located along the Maniqui River, and San Luis Chico (21 households), along the Quiquibey River inside the Pilon Lajas Biosphere Reserve. These villages were chosen for their remote location where traditional hunting with bows and arrows is still common. They are among the most distant communities from market towns in both basins (the Beni and Maniqui river basins).

Initial study identified topics of local importance used to develop a research proposal presented to Tsimane' people including free, prior, informed consent in consultation with local villagers and regional authorities. The design was informed by principles of collaborative ethnography (Lassiter 2005) and indigenous epistemologies (Kovach 2009; Smith 1999). All study activities were carried out following Latin American Society of Ethnobiology (SOLAE 2016) and International Society of Ethnobiology (ISE 2008) codes of ethics. All fieldwork was conducted by AM.

Fieldwork proceeded through participant observation, semi-structured and informal interviews with 'Tsimane' volunteer consultants, and focus groups [3 in Cuchisama and 2 in San Luis Chico] that included hunters and non-hunters (especially women). AM directly observed [ 40] hunting and fishing excursions which provided opportunities for informal interviews. Of all 40 semi-structured interviews in total, 18 (13 male, 5 female) were implemented in Cuchisama and 22 (15 male, 7 female) in San Luis Chico.

\section{Results and Discussion}

In 20 households at Cuchisama, there were five shotguns and three .22-caliber rifles that are sometimes shared among relatives and friends. In 21 households at San Luis Chico, there were eight shotguns and two .22 rifles. Some people do not own 

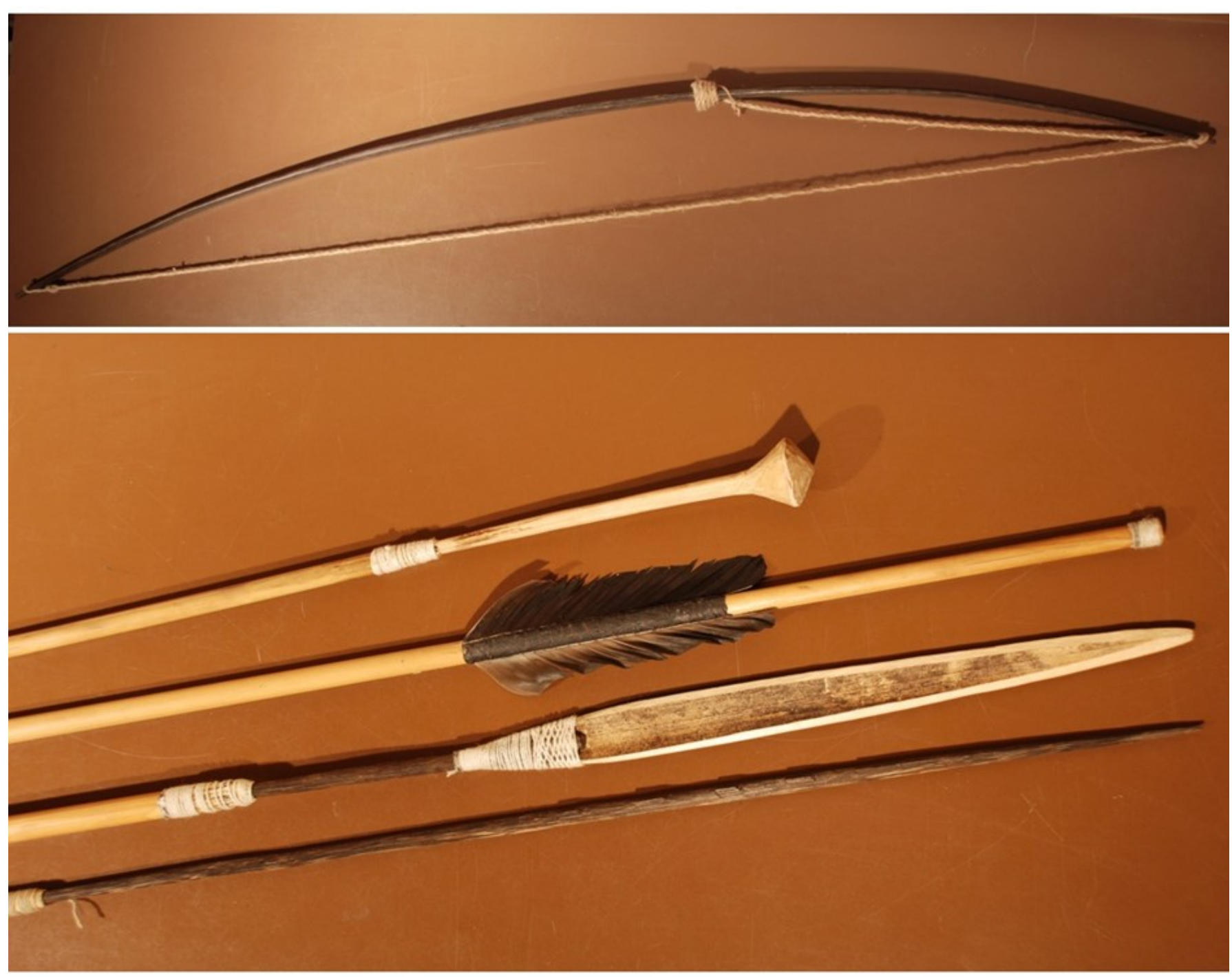

Figure 1 (Top) Tsimane' traditional bow; (Bottom) Tsimane' arrows (from top to bottom: Comora, Shaft, Ton', ljme'/ Yajsi').

firearms nor a bow so they buy ammunition and borrow a gun when they need it.

Traditionally Tsimane' hunting trips are almost exclusively men's activities, usually carried out alone or in company of a close relative. In the past, hunting trips could take several days, but today most trips are one day; rarely, a group (usually a family) hunts for two to three days. Studies of other Amazonian groups describe hunting as a social activity, where groups of people organize and participate in cooperative hunting trips (e.g., Vélez Sosa 2004). Occasionally a hunting party includes more than two people (usually two adults and one or two children).

Table 1 Tsimane' arrows used for traditional hunting.

\begin{tabular}{lllll}
\hline Tsimane' arrow & ljme' & Ton' & Comora & Yajsi' \\
\hline Type of arrow head & Long and narrow pointy & Sharp blade and wide head & Blunt head & Very long, pointy, \\
& head & (bamboo) & and heavy head \\
Prey species & $\begin{array}{l}\text { Medium animals (e.g., pa- } \\
\text { cas and small monkeys) }\end{array}$ & $\begin{array}{l}\text { Big animals (e.g., deer and } \\
\text { tapir) }\end{array}$ & Birds & Fishing \\
\hline
\end{tabular}


'Tsimane' hunting trips can include dogs, but in the focal villages here, hunting with dogs is not common. Only one family in San Luis Chico reported owning hunting dogs. In Cuchisama, only three households reported owning dogs for hunting. Other families own dogs, but they are not used nor trained for hunting. During fieldwork in Cuchisama, only two hunting trips included dogs. No hunters from San Luis Chico reported hunting with dogs during this fieldwork.

Some women participate in hunting, most commonly as companions to their husband. Women rarely hunt without men. Women sometimes opportunistically catch and kill small animals using a machete or bare hands while engaged in other work. As a Tsimane' woman from Cuchisama reported:

One afternoon I was washing clothes on the river when my son told me that a 'jochi' (paca) was about to cross the river, and once I saw the paca I grabbed my machete and I went after the animal, since they cannot swim fast, I caught up with it and hit it in the head, and that is how I hunted it.

Tsimane' indicated that traditional hunting almost exclusively used bows and arrows. Four different types of arrows are used for hunting (Figure 1), depending on the species hunted (Table 1). Hunters commonly carry more than one kind of arrow. Hunters carry a minimum of four arrows. Consultants reported carrying approximately ten arrows in case some arrows need to be left behind temporarily to pursue game after the first shot.

The Tsimane' identify several areas in their territory for hunting, usually areas close to water, and salitrales (naturally occurring saltlicks). These hunting areas are preserved and respected by all villagers and are not used for agriculture or other activities.

A typical hunting trip begins in the morning, with a walk from 45 minutes to several hours duration from the village into hunting areas. In hunting areas, Tsimane' hunters take on a stealthy gait, carefully making their way through the forest observing signs and listening for game. If there are two hunters, then when an animal sound or recent sign is identified they will signal to each other (using hand signals and/or sounds) to indicate the location and species, and how they should proceed. When close enough to the prey, they will shoot an arrow. If the animal is killed, then hunters decide whether to continue hunting or not. If the animal is not killed with the first shot, then a hunter will shoot more arrows until the animal is killed or escapes. Subsequent shots occur after chasing a wounded animal. Studies in similar Amazonian groups indicated that bow-hunters may require 30 shots per kill (Alvard and Kaplan 1991). Night hunting follows a similar pattern, but requires a flashlight which is used only if an animal is identified and is close enough to shoot.

\section{Firearms}

Focus groups indicated that the introduction of firearms into Cuchisama and San Luis Chico occurred more than 30 years ago. At first guns were a novelty and something interesting to try. Traders who brought firearms into Tsimane' territory claimed they were more efficient and reliable than traditional bow and arrows. Eventually firearms became very common in some areas. Many Tsimane' wanted to hunt with guns, but the cash cost was (and is) a limiting factor preventing many 'Tsimane' from transitioning to firearms (see also Hames [1979] for Yekwana). In many cases, Tsimane' purchase guns with loans from traders or through agreements that involve cash and other goods (crops, hunted meat) and especially "jatata" (palm fronds for roof thatching in high demand).

Introduced firearms are usually single-shot, breakaction, 16-gauge shotguns, or .22-calibre single-shot rifles. Shotguns are generally preferred, but according to Tsimane', rifles are more accessible and cost less, although they are less effective than shotguns. Tsimane' developed skills and substantial familiarity with shotguns to the point that they now sometimes modify cartridges to include an additional chunk of lead, making them more effective for large animals (e.g., deer and tapir).

Firearms currently are only available through traders or at retail stores in the closest market town. Prices range from BS 1600 ( USD 230) to BS 2500 ( USD 360), depending on point of purchase. Purchasing from traveling traders is the most common way of obtaining guns, which requires less travel time and money for transportation to market towns (two to three days downriver for some villages).

Due to high prices, Tsimane' still have limited access to firearms. Therefore, they often buy bullets or cartridges and borrow a gun from a relative or friend. Many firearms are very old and have been 
handed down from elders, parents and grandparents, and "westerners" (loggers [often illegal], rubber tappers, and cattle ranchers) that roamed Tsimane' territory in past decades. These old and heavily used firearms are sometimes prone to malfunction (see Hames [1979] for similar reports for Yekwana).

\section{Reflection Process}

Group discussions were organized among hunters and non-hunters including women who specialize in some aspects of bow construction (Medinaceli 2017). Both hunters and non-hunters discussed the introduction of firearms and developed two questions to be answered by the participants: 1) why are we using firearms, and 2) are firearms better than our traditional bows and arrows? We organized more focus groups to answer these questions. Somewhat unexpectedly Tsimane' focus groups could not answer the first question unambiguously: why are we using firearms? Tsimane' from Cuchisama and San Luis Chico both seem to lack a general consensus concerning why they accepted the introduction of firearms. In this reflexive process, people agreed that they needed a detailed analysis of the causes and consequences of firearms as the new norm. This led to an informal cost/benefit analysis regarding the uses of firearms versus traditional bows and arrows. Informants identified eight points of comparison regarding firearms versus bows and arrows (Table 2).

1. Cost of guns: For the Tsimane' who have little regular income, nor much experience interacting with the western market economy, money is a problem.

After thinking a lot, I see that my bow and arrows are better to use than the shotgun or rifle. I can make my own bow and arrows, it does not cost me money. My cousin is in debt because he bought a shotgun and cartridges, and now he is constantly paying little by little to the tradesman. $\mathrm{He}$ still owes some, and is really struggling to pay.

In general, AM observed that most people (about $80 \%)$ had some debt related to gun hunting. Even though the number of gun owners is small, many people buy ammunition and then borrow a gun, thus most people have firearms related debt.

2. Cost of bullets vs. arrows:

Sometimes when I use my bow and arrows, I lose some arrows or they break. But if that happens, there is no problem, because I always have some chuchio* and chonta* in my house, so I can make more arrows. But if I run out of bullets for my shotgun, I need to buy them, and they are expensive. Therefore, I think it is better to use bows and arrows, that way I do not need to spend money purchasing bullets (Figure 2). [*Cbuchio is a type of bamboo used to make the shaft of an arrow. Chonta is a palm used for making bows and arrows.]

Hardwood for arrows and bow construction (genus Bactris, used for both) does not appear to be a limiting factor. Tsimane', however, are choosey about selection of a particular tree for bows or arrows, but the Bactris genus is relatively common (Medinaceli 2017).

Table 2 Analysis of cost and benefits between traditional bows and arrows vs. firearms.

\begin{tabular}{|c|c|c|}
\hline Tsimane' points of comparison & Bows and arrows & Firearms \\
\hline 1. Cost (in \$) of weapon & None* & $\$ \$ \$$ \\
\hline 2. Cost (in $\$$ ) of bullets/arrows & None* & $\$ \$$ \\
\hline 3. Cost (in \$) of maintenance & None* & $\$ \$$ \\
\hline 4. Effectiveness when shooting & $\begin{array}{l}\text { Very effective (shoots every time), has } \\
\text { reduced "knockdown" power }\end{array}$ & $\begin{array}{l}\text { Sometimes does not shoot (not good), } \\
\text { but has excellent knockdown }\end{array}$ \\
\hline $\begin{array}{l}\text { 5. Quietness (to prevent animals to } \\
\text { run away) }\end{array}$ & Very quiet & Very loud (not good) \\
\hline 6. Shoot from a long distance & No & Yes (rifle) \\
\hline 7. Bullets/arrows returned & Possibly** & No (positive) \\
\hline 8. Effect in the Tsimane' culture & Supports our culture as hunters & Changes our culture \\
\hline
\end{tabular}

"Tsimane' from Cuchisama and San Luis Chico do not consider their time as an expense.

${ }^{* *}$ It was reported that rarely an arrow that misses the target could be thrown back if the prey is a monkey. 


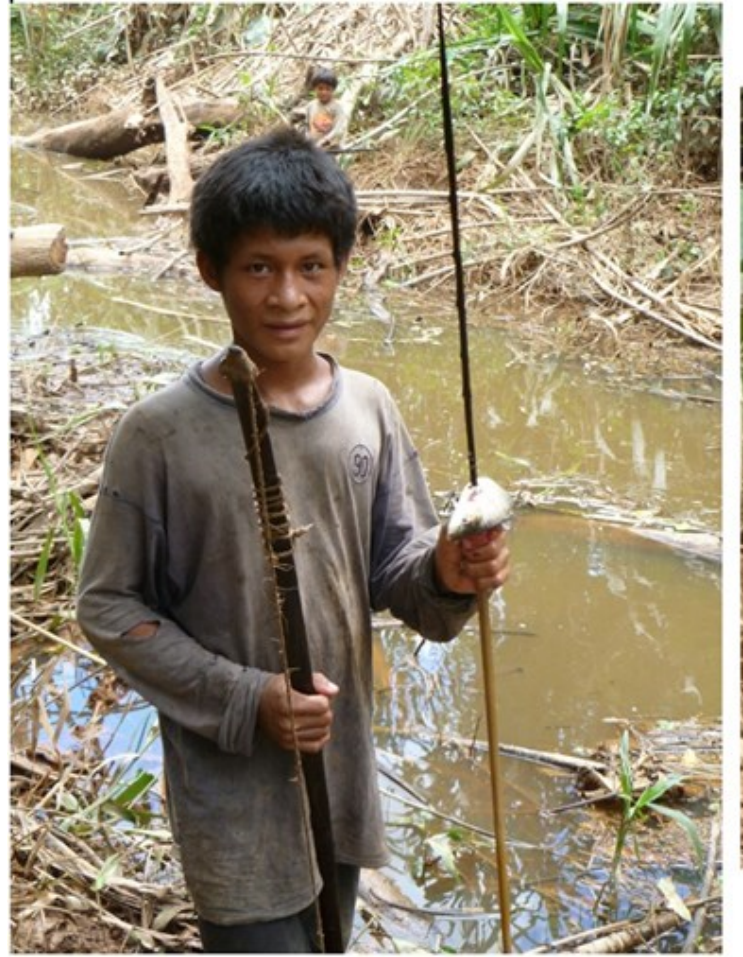

Figure 2 Right after successful fishing shots.

3. Reliability of firearms: Tsimane' noted that guns are not always reliable in humid tropical forests. Hames (1979) reports similar issues for the Ye'kwana of Venezuela, even with relatively well maintained firearms. One Tsimane' explained,

I own a shotgun, but sometimes when I go hunting it does not want to shoot, it breaks fairly often. Several times I was very close to a group of troperos (wild boars) and my shotgun did not shoot. I was disappointed. If I had a bow and arrows that day, for sure I would have some meat for my family. I already tried to fix my shotgun, but is not the same, I have to send it to Rurre so it can get fixed, but that costs me money, and every time that it gets ruined to get it fixed means more money. I think I will ask my uncle to teach me how to make a bow, when I was young I was really good at shooting with the bow and arrows, but I do not know anymore how to make one.

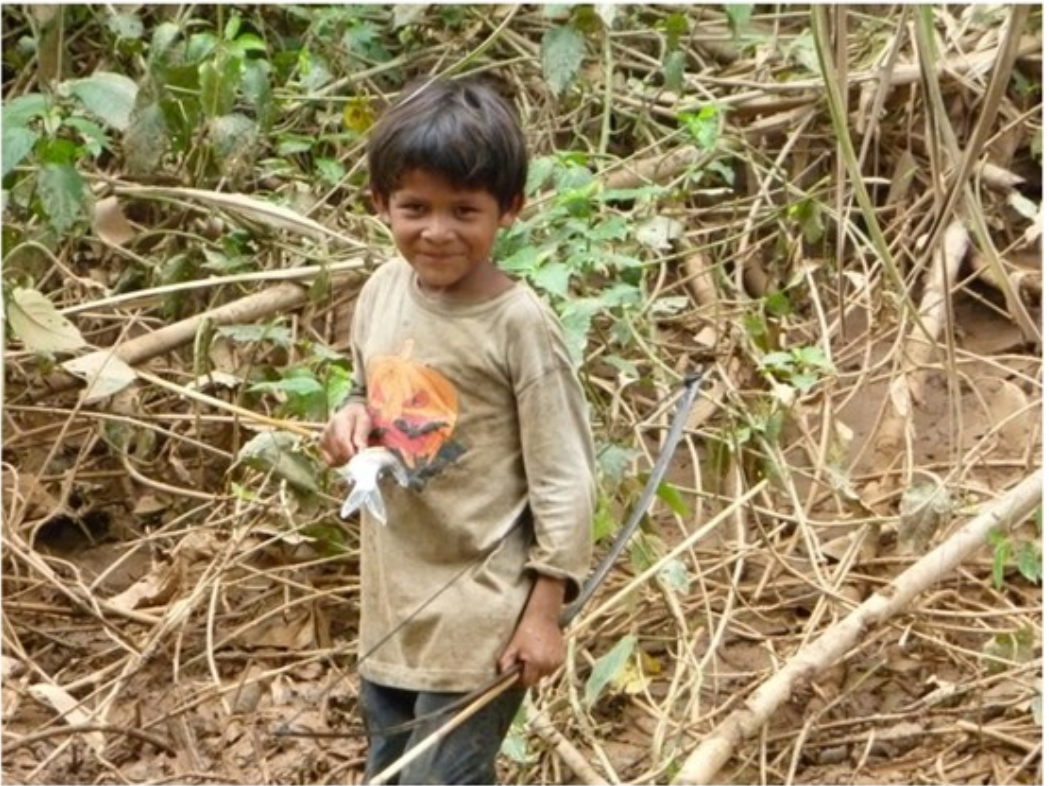

It is difficult to assess the causes and rates of firearm failures in remote, small-scale populations. Most Tsimane' shotguns follow the simplest breakaction, single-shot, breech loading pattern common in Amazonia. High humidity can cause multiple problems in arms and ammunition including stuck firing pins, malfunctioning extractors, bad primers, and damp powder. Heavy usage can wear out firearms surprisingly quickly especially regarding compacted (shortened) or bent firing pins, and weakened and broken trigger and hammer springs. Failure rates are likely to be especially high where cleaning tools and solvents are less accessible. More complicated repeating and semi-automatic .22-calibre rifles are even more prone to failure probably from a combination of mechanical complexity, corrosive .22calibre rim-fire primers, and high humidity. It is not uncommon to find firearms that have been retired from service because of unreliability.

4. Cost of repairs:

My rifle gets stuck often and it does not want to shoot. I do not know what it is, but every once in a while [it] does that. We tried to fix it here [in the village] but we cannot do it. The trader has to take it to somebody 
who can fix it, but that costs a lot of money. But even though it's expensive, I have to pay somehow, because I do not have a bow and arrows; it is a long time since I used one. Sometimes when my rifle is not working I borrow a bow and arrows to go hunting, I am still good at it, but I cannot make one [a bow] anymore, it's difficult. I have to ask somebody to teach me how to make one, or on my own I will try to make one, because my rifle only gives me trouble, plus I still owe the trader and he charges me more and more every time.

5. Loud gunshots versus quiet arrows: The loud report of a gunshot is an important consideration. If a gun-hunter misses, then nearby animals will flee because of the noise. If a bow-hunter misses, then he can usually shoot again. Several Amazonian studies mention this consideration for gun-hunting (Alvard 1995; Hames 1979; Harner 1972). Hames (1979) estimates that the report from a shotgun carries for up to $2 \mathrm{~km}$ in Amazonian forests. Interviewees explained it thusly:

When we go hunting with the shotgun you have to be completely sure about not missing your target, because if you see an animal and get desperate and try to shoot and miss, you miss all opportunity for that day, because the shotgun is really loud when shooting, and all animals run far away escaping the noise. Therefore you only have one shot, after that you cannot shoot anymore. If you miss but still want to get some meat, you will need to walk a lot, chasing the animals. If you are hunting with bow and arrows it is easier, because if you miss a shot, you can just laugh, then you can shoot again, then in the second shot for sure you get something, because we cannot miss twice.

6. Effective Range: In most cases the bullet or shot from a firearm travels further than arrows. Hames (1979) estimates that a Yanomamo bow has an effective range of about 21-25m, compared to 25$43 \mathrm{~m}$ for a shotgun. A .22-caliber rifle with a typical "long-rifle" cartridge has a maximum effective range of about $70 \mathrm{~m}$ beyond which the bullet has drastically reduced energy (Hampton et al. 2016:282). Tsimane' say that even at long distances, a rifle has more power to kill or gravely wound small animals compared with bows and arrows.

When I take my rifle hunting, the good thing is that I can shoot from far away, but you have to be good at it and not miss. On the other hand, if I go hunt with my bow and arrows I have to get closer to the animals, and sometimes it is difficult to get close to them.

7. Arrows returned by prey: An interesting and surprising point, repeated several times during fieldwork, is that some primate species actually throw arrows back at hunters:

One day two of us were hunting. We went close to the lake because over there there are always groups of marimonos (spider monkeys) and maneches (howler monkey). We were walking and saw a group of marimonos on the trees. We chased them and when they were quiet, we shot with the bows and arrows. I hit one but I only hit his arm, then the marimono took the arrow from his arm and threw it back at us.

8. Effect on local identity: This point was identified early in the fieldwork, and it is one reason for pursuing more in-depth discussions of 'Tsimane' hunting and fishing tools (Figure 3). During a focus group, several participants commented that gun-hunting was causing Tsimane' to lose their traditional identity: 'We are Tsimane', we are traditionally hunter and gatherers. But now using firearms, we are becoming shotgun hunters, that is not what a true Tsimane' is." This comment started a long discussion that recurred during participant observation and informal interviews. Loss of identity related to gun-hunting was commonly considered a problem for Tsimane'.

Tsimane' people from Cuchisama and San Luis Chico identified six points of comparison in which traditional bows and arrows are superior to firearms 


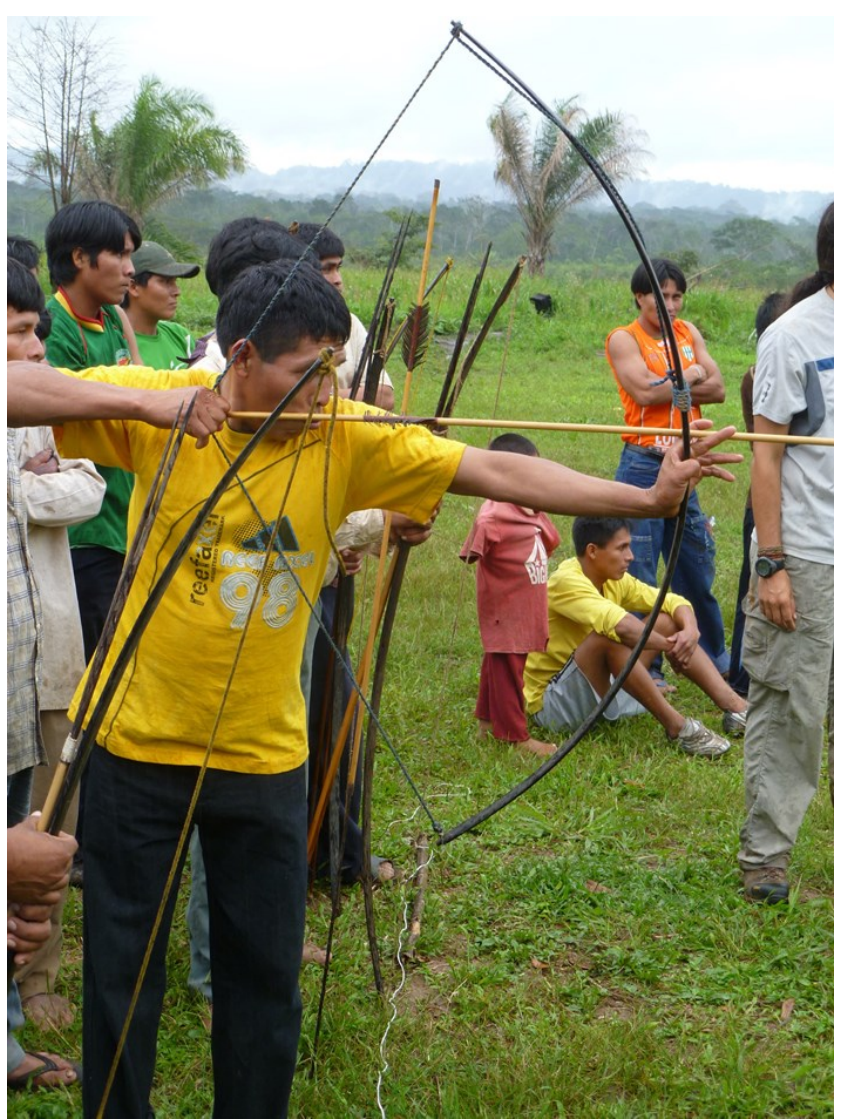

Figure 3 Tsimane' shooting a traditional bow and arrow.

for hunting compared with two advantages for firearms. Informants from both villages reached a consensus that gun-hunting is not better than traditional bow-hunting. Importantly, Tsimane' did not include game conservation as an emic concern regarding gun-hunting, contrasting with findings from ecological studies showing substantial game depletion with gun-hunting (Cronin et al. 2016; Kümpel et al. 2008; Levi et al. 2009, 2011; Peres 2000; Shepard et al. 2012). This lack of concern may be because these conservation effects are not yet readily observable. Based on comparisons of game offtake in gun- and bow-hunting communities in Peru, Alvard (1995) indicated that gun-hunting is not detrimental to game conservation. Reyes-Garcia (2001) reports similar offtake in gun- and bow-hunting intensive Tsimane' communities. However, comparison of kill rates upon encounter and return rates per hour for gun- and bow -hunting (Alvard and Kaplan 1991) suggests there may be lower game encounter rates in intensive gunhunting areas indicative of reduced game biomass. Regarding Alvard's (1995) findings, Shepard et al. (2012:258) suggested that in 15 years after introduction of firearms, gun-hunting return rates may have fallen to a comparable level with bow-hunting: the "short-term benefits of shotguns are counterbalanced by more severe local-game depletion, such that bow hunters and gun hunters ultimately spend the same amount of time hunting for a given return". Once the 'Tsimane' themselves perceive the long-term effects of gun hunting on prey species, it may be too late to address the problem.

After the focus group and interview comparisons of bows and firearms, AM supplemented this data with additional interviews and an analysis of other costs associated with the fabrication or purchasing guns and bows/arrows (Table 3).

Interviews indicate that despite multiple downsides of firearms among Tsimane', their use has increased over time, resulting in less bow-hunting. People that still used bows as their main tool for hunting also occasionally used a firearm. However, people who used firearms as their main hunting tool stopped using bows completely, which suggests a loss of specialized knowledge required for bow/arrow manufacture and bow-hunting. Research in more acculturated 'Tsimane' communities indicates a substantial decrease in importance of tool manufacture for social status (von Rueden et al. 2008). Traders visiting 'Tsimane' communities may have a strong influence, and they promote firearms (and other tools) as more effective than traditional Tsimane' tools and as symbols of development. In fact, purchase of rifles and shotguns appears to signal social status in more acculturated 'Tsimane' communities (Godoy et al. 2007). However, purchasing manufactured goods was not associated with 'Tsimane' wellbeing and was positively associated with regret (Godoy et al. 2010).

Traditional hunting is learned from a young age (e.g., Gurven et al. 2006; Zent 2007) and Tsimane' children learn about hunting in part through play with toy bows and arrows which used to be the main toy for boys. Currently children play with plastic toys (trucks, planes, dolls, weapons, etc.) thus slowly changing their focus and interest from traditional skills-based play. Direct observation indicated that teenagers learn to use firearms beginning at 14-15 years of age, usually with adult supervision. By the age of 17 or 18 'Tsimane' men begin using firearms for hunting without supervision. In comparison, children use bows as a toy from an early age (usually to shoot lizards or insects) and they can hunt or fish without 
adult supervision as young as 9 or 10 years old. Currently more than $40 \%$ of children (between 4 to 14 years old) in both villages did not play with bows and arrows and cannot make them.

Making Bows and Arrows

'Tsimane' also mentioned that with the introduction of firearms there is a reduction in bow fabrication. About $10 \%$ of adults (16 years of age and older) in Cuchisama, and $30 \%$ of the adults of San Luis Chico report not knowing how to make bows and arrows. Knowledge loss regarding the fabrication of bows and arrows seems to be affected solely by the introduction of firearms, since all interviewees report targeting the same animal species regardless of the type of weapon used. The process of making bows and arrows is traditionally a family affair, since every family member has a role in their manufacture, though usually only the head of the household and the male children will use them. Table 4 shows the roles of family members in the fabrication of traditional bows and arrows. Women's knowledge about fabrication of bowstring and puñipuy' (traditional glue used to secure feathers to arrows, and to keep cotton thread from shifting when used to support the attachment of arrowheads to the shaft, and also for the nock or grip of the arrows) seems to be unaffected, mainly because string and glue are tools also used for other purposes other than fabrication of bows and arrows (Figure 4).

\section{Conclusions}

In Amazonia, conservation of cultural traditions is increasingly urgent, due mainly to external factors such as urbanization, conservation strategies (i.e., protected areas), illegal activities (i.e., logging), and introduction of the market economy. These factors are changing traditions at the core of Amazonian cultures. The Tsimane' of Cuchisama and San Luis Chico identify the introduction of firearms as a challenge to their cultural identity. Gun-hunting has

Table 3 Analysis of cost and benefits between traditional bows and arrows vs. firearms.

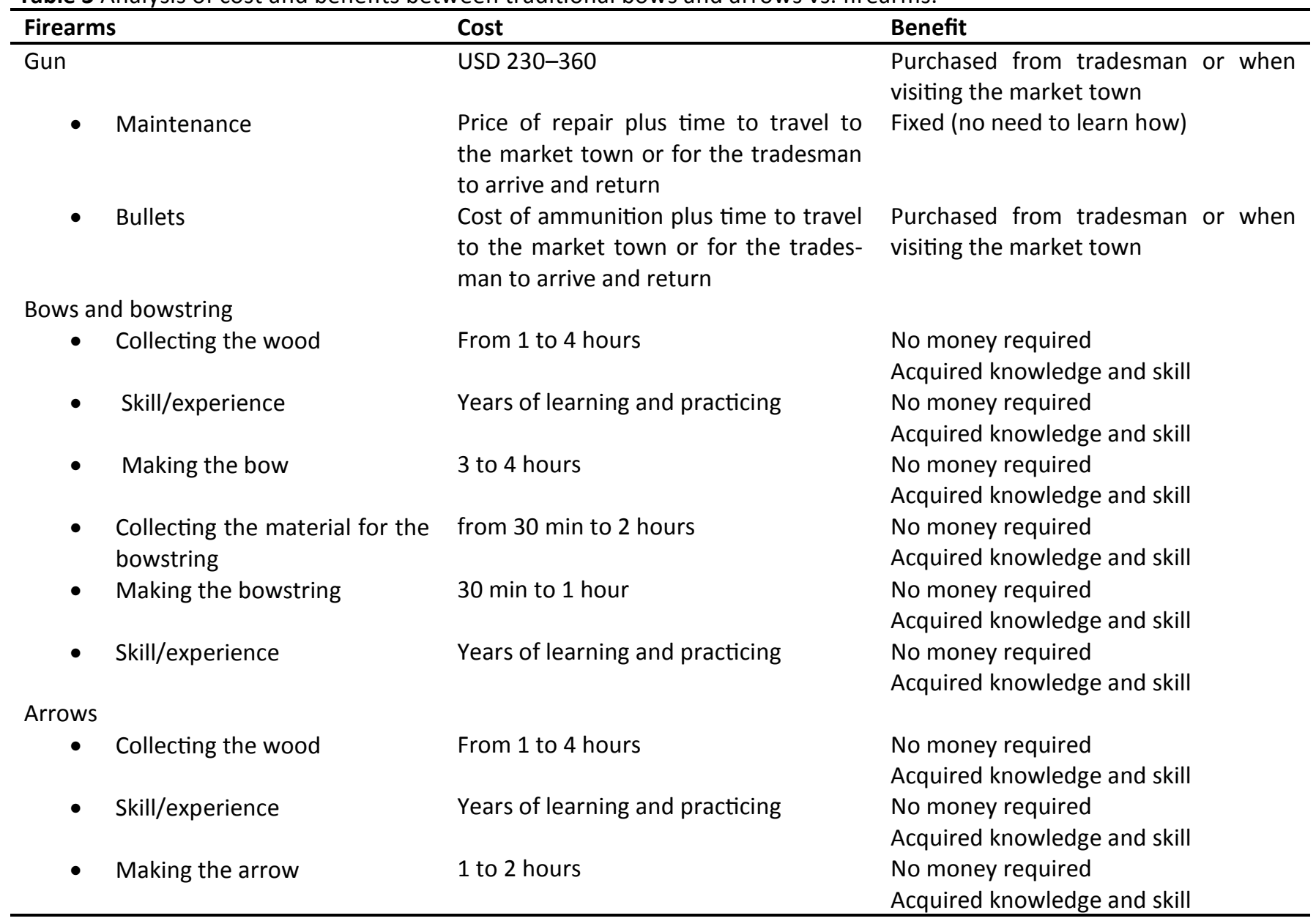




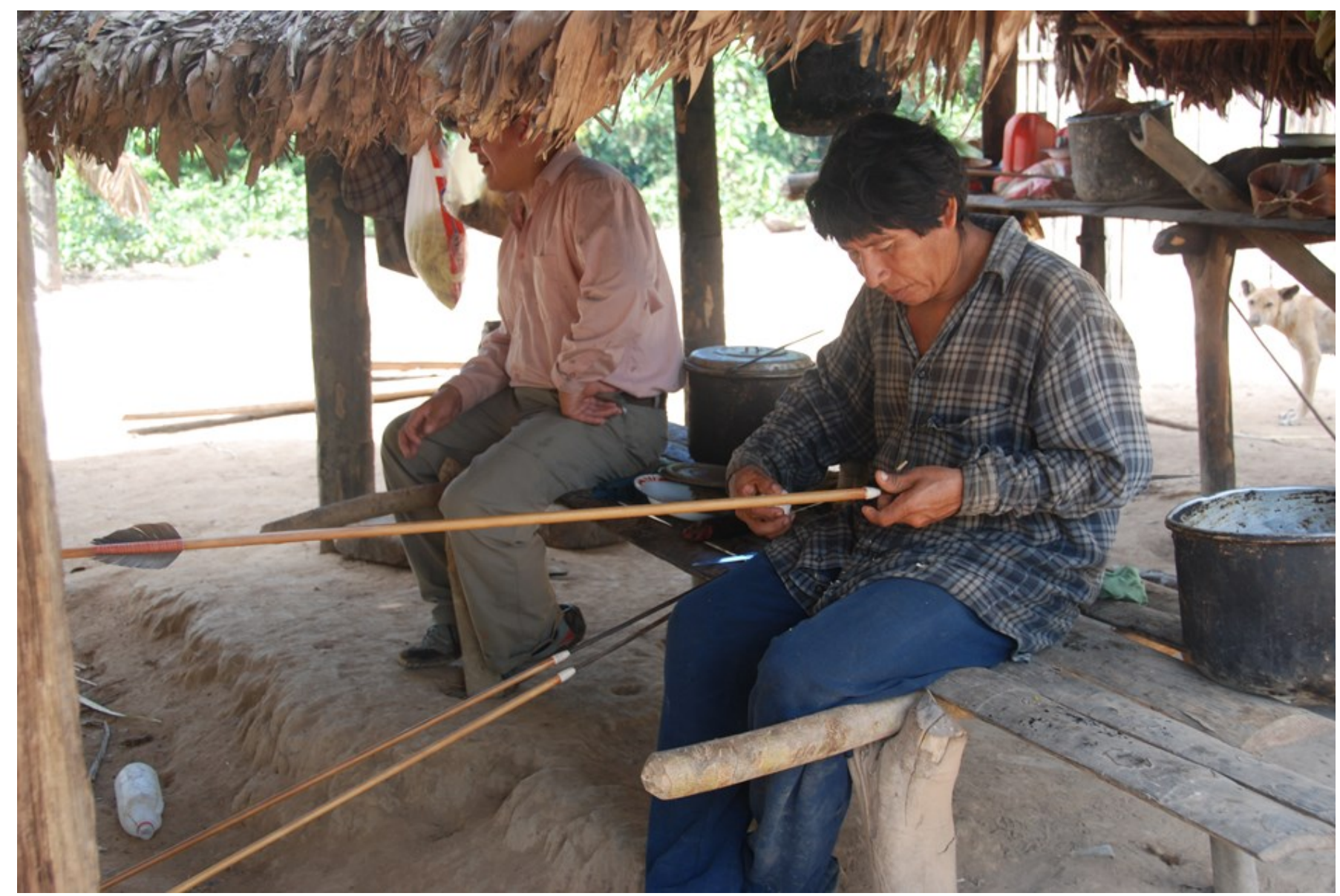

Figure 4 Finishing the fabrication of an ljme', Tsimane' arrow to hunt small animals.

resulted in a substantial loss of indigenous knowledge for tool manufacture and hunting techniques. The quest for firearms has led Tsimane' into considerable debt they cannot afford in order to purchase guns and ammunition and to pay for repairs. This expense requires a shift from subsistence horticulture and hunting to production of surpluses for market sales. Widespread gun-hunting has also resulted in the loss of traditional skills acquisition through play with toy bows and arrows.
Other aspects of traditional hunting practice appear to remain intact. Tsimane' bow and gun hunters both indicate using magical items (like amber), refraining from sex before hunting, and hunting based on dreams to increase hunting success. However, change in hunting technology likely has some influence on Tsimane' prey choice similar to reports for other Neotropical hunters (Jerozolimski and Peres 2003:420; Siren and Wilkie 2016), and loss of specific bow-hunting and traditional manufacturing knowledge and skills.

Table 4 Role of family members in the elaboration of Tsimane' bows and arrows.

\begin{tabular}{ll}
\hline Activity & Person in charge \\
\hline Collecting materials & Household head (male) and children \\
Bow & Household head \\
Rope & Women \\
Glue & Women \\
Arrows & Older children \\
Cotton & Women \\
\hline
\end{tabular}


Focus groups concluded that Tsimane' are hunters and part of being a Tsimane' hunter is using bows and arrows. They also concluded that all members of the villages should become familiar with the use and fabrication of bows and arrows. Even though Tsimane' indicated that the use of the traditional bow and arrows has more benefits than firearms, firearms are still making their way into Tsimane' villages, replacing traditional hunting tools. From our observations in the field and from the reports from Tsimane' research participants, it seems the 'Tsimane' deal with external pressure to become more market integrated. In San Luis Chico, a market town is relatively accessible, and merchants are persistent and persuasive. On the other hand, there is pressure to maintain traditions and Tsimane' identity as tropical forest hunters. We hope this study might help promote some balance between western market integration and traditional livelihoods. Also, given the effects of gun-hunting on traditional knowledge, economics, and cultural identity-in addition to effects on game conservation-we suggest development and implementation of collaborative strategies to recover traditional hunting practices and knowledge associated with them.

\section{Declarations}

Permissions: "Collaboration agreement" between researchers and Tsimane' authorities and the villages involved. Oral agreement based on Tsimane' traditional norms and customs and following codes of ethics from ISE and SOLAE.

Sources of funding: None declared.

Conflicts of Interest: None declared.

\section{References Cited}

Alexiades, M. 1999. Ethnobotany of the Ese Eja: Plants, Health, and Change in an Amazonian Society. Unpublished Doctoral Dissertation, Department of Biology, The City University of New York, New York.

Alvard, M., and H. Kaplan. 1991. Procurement Technology and Prey Mortality among Indigenous Neotropical Hunters. In Human Predators and Prey Mortality, edited by M. C. Stiner, pp. 79-104.

Westview Press, San Francisco.

Alvard, M. 1995. Shotguns and Sustainable Hunting in the Neotropics. Ory $x$ 29:58-66. DOI:10.1017/ S0030605300020883.
Carneiro, R. 1974. Hunting and Hunting Magic Among the Amahuaca of the Peruvian Montaña. In Native South Americans; Ethnology of the Least Known Continent, edited by J. P. Lyon, pp. 122-132. Little, Brown and Company, Boston.

Cronin, D., C. Riaco, J. Linder, R. Bergl, M. Gonder, M. O'Connor, and G. Hearn. 2016. Impact of Gunhunting on Monkey Species and Implications for Primate Conservation on Bioko Island, Equatorial Guinea. Biological Conservation 197:180-189. DOI: 10.1016/j.biocon.2016.03.001.

Descola, P. 1994. In the Society of Nature: A Native Ecology in Amazonia. Cambridge University Press, Cambridge, United Kingdom.

Ellis, R. 1996. A Taste for Movement: An Exploration of the Social Ethics of the Tsimane' of Lowland Bolivia. Unpublished Doctoral Dissertation, Department of Social Anthropology, University of St Andrews, St Andrews, Scotland.

Godoy, R., V. Reyes-Garcia, T. Huanca, W. R. Leonard, T. McDade, S. Tanner, V. Vadez, and C. Seyfried, 2007. Signaling by Consumption in a Native Amazonian Society. Evolution and Human Behavior 28:124-134. DOI:10.1016/

j.evolhumbehav.2006.08.005.

Godoy, R., E. Zeinalova, V. Reyes-Garcia, T. Huanca, H. Koziewicz, W. R. Leonard, S. Tanner, and TAPS Bolivian Study Team. 2010. Does Civilization Cause Discontentment Among Indigenous Amazonians? Test of Empirical Data from the Tsimane' of Bolivia. Journal of Economic Psychology 31:587-598. DOI:10.1016/j.joep.2010.04.001.

Gurven M., H. Kaplan, and M. Gutierrez. 2006. How Long does it Take to Become a Proficient Hunter? Journal of Human Evolution 51:454-470. DOI:10.1016/j.jhevol.2006.05.003.

Gurven, M., and C. V. Rueden. 2006. Hunting, Social Status and Biological Fitness. Social Biology 53:81-99. DOI:10.1080/19485565.2006.9989118.

Hames, R. 1979. A Comparison of the Efficiencies of the Shot-gun and the Bow in Neotropical Forest Hunting. Human Ecology 7:219-252. DOI: 10.1007/ bf00889493.

Hampton, J., P. Adams, D. Forsyth, B. Cowled, I. Stuart, T. Hyndman, and T. Collins. 2016. Improving Animal Welfare in Wildlife Shooting: 
The Importance of Projectile Energy. Wildlife Society Bulletin 40:678-686. DOI:10.1002/wsb.705.

Harner, M. 1972. The Jivaro: People of the Sacred Waterfalls. UC Press, Los Angeles.

Holmberg, A. 1969. Nomads of the Long Bow: Siriono of Eastern Bolivia. American Museum of Natural History, New York.

International Society of Ethnobiology. 2006. ISE Code of Ethics (with 2008 additions) [web page]. Available at: http://ethnobiology.net/code-ofethics/. Accessed on March 15, 2017.

Jerozolimski, A., and C. Peres. 2003. Bringing Home the Biggest Bacon: A Cross-site Analysis of the Structure of Hunter-kill Profiles in Neotropical Forests. Biological Conservation 111:415-425. DOI:10.1016/S0006-3207(02)00310-5.

Kovach, M. 2009. Indigenous Methodologies: Characteristics, Conversations, and Contexts. University of Toronto Press, Toronto, Canada.

Kümpel N., E. Milner-Gulland, J. Rowcliffe, and G. Cowlishaw. 2009. Impact of Gun-Hunting on Diurnal Primates in Continental Equatorial Guinea. International Journal of Primatology 29:1065-1082. DOI:10.1007/s10764-008-9277-2.

Lassiter, L. 2005. The Chicago Guide to Collaborative Ethnography. University of Chicago Press, Chicago.

Levi, T., G. Shepard, J. Ohl-Schacher, C. Peres, and D. Yu. 2009. Modeling the Long-term Sustainability of Indigenous Hunting in Manu National Park, Peru. Journal of Applied Ecology 46:804-814. DOI:10.1111/j.1365-2664.2009.01661.x.

Medinaceli, A. 2017. Fabricando Arcos y Flechas Amazonicos con los Tsimane' de Bolivia. Fabricating Amazonian Bows and Arrows with the Tsimane' from Bolivia. Film. Available from armando.medinaceli@wsu.edu.

Peres, C. 2000. Effects of Subsistence Hunting on Vertebrate Community Structure in Amazonian Forests. Conservation Biology 14:240-253. DOI:10.1046/j.1523-1739.2000.98485.x.

Reyes-Garcia, V. 2001. Indigenous People, Ethnobotanical Knowledge, and Market Economy: A Case Study of the Tsimane' Amerindians in Lowland Bolivia. Unpublished Doctoral
Dissertation, Department of Anthropology, University of Florida, Gainesville, FL.

Reyes-Garcia, V., J. Paneque-Galvez, P. Bottazzi, A. C. Luz, M. Gueze, M. J. Macia, M. Orta-Martinez, and P. Pacheco. 2014. Indigenous Land Reconfiguration and Fragmented Institutions: A Historical Political Ecology of Tsimane' Lands (Bolivian Amazon). Journal of Rural Studies 34:282291. DOI:10.1016/j.jrurstud.2014.02.007.

Robinson, J., and K. Redford. 1991. Neotropical Wildlife Use and Conservation. The University of Chicago Press, London.

Roselis, R., P. Temehe, F. Xinymy, H. Waraié, G. Sanapyty, and M. Ewepe. 2000. Subsistence Hunting among the Waimiri Atroari Indians in Central Amazonia, Brazil. Biodiversity and Conservation 9:579-596. DOI:10.1023/A:1008999201747.

Shepard, G., T. Levi, E. Neves, C. Peres, and D. Yu. 2012. Hunting in Ancient and Modern Amazonia: Rethinking Sustainability. American Anthropologist 114:652-667. DOI:10.1111/j.15481433.2012.01514.x.

Siren, A., and D. Wilkie. 2016. The Effects of Ammunition Price on Subsistence Hunting in an Amazonian Village. Oryx 50:47-55. DOI:10.1017/ S003060531400026X.

Smith, L. 1999. Decolonizing Methodologies: Research and Indigenous Peoples, $2^{\text {nd }}$ edition. Zed Books, London.

SOLAE (Sociedad Latinoamericana de Etnobiología). 2016. Código de Ética. Etnobiologia 14(1).

Vélez Soza, D. 2004. Diagnostico del uso de Fauna Silvestre en las Veredas Mundo Nuevo, el Manzano y la Jangada en la Reserva Forestal Protectora de los Rios Blanco y Negro en el Municipio de la Calera (Cundinamarca - Colombia). MEMORIAS: Manejo de Fauna Silvestre en Amazonía y Latinoamérica 330335.

Vickers, W. 1984. The Faunal Components of Lowland South American Hunting Kills. Interciencia 9:366-376.

Von Rueden, C., M. Gurven, and H. Kaplan. 2008. The Multiple Dimensions of Male Social Status in an Amazonian Society. Evolution and Human Behavior 29:402-415. DOI:10.1016/

j.evolhumbehav.2008.05.001. 
Zent, E. 2007. El Yo-Cazador: Perforaciones, Prescripciones y Seres Primordiales Entre los Jodi, Guayana Venezolana. Amazonía Peruana 30:111139. 